\title{
Differentially expressed genes responsible for insensitivity of CD34+ cells to kinase inhibitors in patients with chronic myeloid leukemia
}

\author{
Caroline FA Moreira-Nunes ${ }^{1,2^{*}}$, Tereza CB Azevedo ${ }^{3}$, Ana CS Beltrão ${ }^{3}$, Larissa TVM Francês ${ }^{2}$, Rodrigo GMA Sousa ${ }^{4}$, \\ Israel T Silva ${ }^{4}$, Artur Silva ${ }^{1}$, Wilson A Silva $\mathrm{Jr}^{4}$, José AR Lemos ${ }^{1,2}$
}

From São Paulo Advanced School of Comparative Oncology

Águas de São Pedro, Brazil. 30 September - 6 October 2012

\section{Background}

Chronic Myeloid Leukemia (CML) is a clonal myeloproliferative disorder characterized by formation of $B C R-A B L$ fusion that encodes the 210 oncoprotein, which has a tyrosine kinase activity that confers an adaptive advantage to leukemic cells. Imatinib mesylate (IM) acts specifically on p210. Imatinib is able to reduce the differentiated cells $(\mathrm{CD} 66 \mathrm{~b}+)$ efficiently, but it has not the same effect on the stem cells (CD34+), which can be kept alive during treatment. Our aim was to identify expressed genes in CD34+ and $\mathrm{CD} 66 \mathrm{~b}+$ cells as candidates for kinase inhibitors transport.

\section{Materials and methods}

$\mathrm{CD} 34+$ and $\mathrm{CD} 66 \mathrm{~b}+$ cells were isolated from bone marrow $(\mathrm{BM})$ and peripheral blood (PB) of five patients with CML, in optimal response, and 1 control. The samples were sequenced on SOLiD ${ }^{\mathrm{TM}}$ platform for whole transcriptome analysis. We analyzed the Gene Ontology annotation, and the software Cufflinks were used to identify the differential expression of genes in patients $(\mathrm{BM} \times \mathrm{PB})$ and controls (BM x PB).

\section{Results}

In pooled patient samples, we identified the expression of SLC22A1 influx gene in both, BM and PB samples, without any significant change $(p \leq 0,05)$, and expression of $S L C O 1 A 2$ influx gene only in PB sample. Thus its presence could not be identified in any of the control samples. The overexpression of $\mathrm{ABC}$ efflux gene family $(A B C B 1$; $A B C G 2 ; A B C C 1$ ), were found only in BM cells of patients.
The presence of other two genes responsible for the drug efflux was also found exclusively in BM pool sample of patients, SLC47A1 and SLC47A2.

\section{Conclusions}

Over-representation of drug influx and absence of drug efflux channels in mature cells, and the reverse in stem cells of patients with CML may explain the insensitivity of CD34+ cells to IM treatment and consequent failure to eliminate minimal residual disease.

\section{Financial support}

Novartis Oncology of Brazil.

\section{Author details}

${ }^{1}$ Institute of Biological Science, University Federal of Pará. Belém-Pará, Brazil. ${ }^{2}$ Center of Hemotherapy and Hematology of Pará - HEMOPA Foundation. Belém-Para, Brazil. ${ }^{3}$ Department of Hematology - Ophir Loyola Hospital. Belém-Para, Brazil. ${ }^{4}$ Department of Genetics, School of Medicine of Ribeirão Preto, University of São Paulo, Ribeirão Preto, São Paulo, Brazil.

Published: 4 April 2013

doi:10.1186/1753-6561-7-S2-O1

Cite this article as: Moreira-Nunes et al:: Differentially expressed genes responsible for insensitivity of $\mathrm{CD} 34+$ cells to kinase inhibitors in patients with chronic myeloid leukemia. BMC Proceedings 2013 7(Suppl 2):01.

\footnotetext{
* Correspondence: carolfam@gmail.com

${ }^{1}$ Institute of Biological Science, University Federal of Pará. Belém-Pará, Brazil

Full list of author information is available at the end of the article
} 